\title{
Relationship between mammary blood flow, infrared thermography and ovine placental lactogen during the periparturient period in ewes
}

\author{
RYSZARD BOBOWIEC, MARTA WÓJCIK, ANDRZEJ MILCZAK*, \\ URSZULA KOSIOR-KORZECKA, MONIKA GREGUŁA-KANIA**, JAROSŁAW TATARCZAK ${ }^{* * *}$
}

\begin{abstract}
Sub-Department of Pathophysiology, Department of Preclinical Veterinary Sciences,
*Department and Clinic of Animal Internal Diseases, Faculty of Veterinary Medicine, University of Life Sciences in Lublin, Akademicka 12, 20-033 Lublin, Poland
\end{abstract}

${ }^{* *}$ Institute of Animal Breeding and Biodiversity Conservation, Faculty of Biology, Animal Sciences and Bioeconomy, University of Life Sciences in Lublin, Akademicka 13, 20-950 Lublin, Poland

***Sub-Department of Horticulture and Forestry Machinery, Faculty of Production Engineering, University of Life Sciences in Lublin, Głęboka 28, 20-612 Lublin, Poland

Bobowiec R., Wójcik M., Milczak A., Kosior-Korzecka U., Greguła-Kania M., Tatarczak J. Relationship between mammary blood flow, infrared thermography and ovine placental lactogen during the periparturient period in ewes

\section{Summary}

The aim of the study to verify the hypothesis whether a drop in the oPL levels in the blood in the periparturient period is associated with changes in the right mammary vein blood flow (RMVBF) and udder skin temperature (UST). We were also interested in comparing variations in the above-mentioned parameters in single- and twin-pregnant ewes. Beginning six days before parturition $\left(-6^{\text {th }}\right.$ day) until four days postpartum $\left(4^{\text {th }}\right.$ day), every second day each of 15 experimental pregnant ewes was subjected to color Doppler ultrasound performed with continuous wave-equipment (My Lab One/Touch) and infrared thermography (IRT), which allowed for noninvasive collection of data. Plasma oPL levels were determined using quantitative sandwich ELISA Kit specified for sheep placental lactogen 1 (oPL). The measured values of UST were affected by the periparturient period but not by the number of lambs delivered. The highest udder temperatures were recorded at four days before parturition, which was followed by their gradual decrease. As a result, UST achieved the lowest values in single- and also in twin-pregnant ewes on the day of parturition $\left(35.70 \pm 0.65^{\circ} \mathrm{C}\right.$ and $35.42 \pm 0.45^{\circ} \mathrm{C}$, respectively). Among all the time points of measuring IRT and $\mathrm{OPL}$, a significant positive correlation $(\mathrm{P} \leq 0.01)$ was estimated at -4 and 0 days before parturition for single- $(r=0.99)$ and twin- $(r=0.59)$ pregnant ewes. In comparison to control ewes, right mammary vein blood flow (RMVBF) significantly $(P \leq 0.05)$ increased in all pregnant ewes under study. Especially in twin-pregnant ewes, a positive correlation between the plasma concentration of oPL and blood flow occurred between the $-4^{\text {th }}$ and 0 day $(r=0.76)$. Maximal velocity of blood flow in the mammary vein in single- $(25.90 \pm 5.95 \mathrm{~cm} / \mathrm{s})$ and twin-pregnant ewes $(24.62 \pm 4.86 \mathrm{~cm} / \mathrm{s})$ was recorded at the $2^{\text {nd }}$ and $4^{\text {th }}$ day postpartum, respectively. The highest values of plasma oPL $(0.56 \pm 0.05 \mu \mathrm{g} / \mathrm{ml})$ recorded at the beginning of the experimental period $(-6$ days before parturition) dropped significantly $(P \leq 0.05)$ during the subsequent days, until parturition. The curve of the temporal changes in the concentrations of plasma oPL remains unchanged regardless of the number of fetuses. Three-phasic thermal changes in the periparturient period and an increase in blood flow parameters are related to the disappearance of oPL from the circulation, which should be taken into account when assessing a pathological state of this gland.

Keywords: ovine placental lactogen, mammary blood flow, infrared thermography, periparturient period

The effect of ovine placental lactogen (oPL), or chorionic somatomammotropin 1 (CSH1) (3) is ambiguous and it is still poorly defined $(2,19)$. This hormone, produced by binuclear cells of the tropho- blast, is delivered both to the fetus and the maternal circulation (5). Fowlkes et al. (8) state that oPL exerts mainly a pro-growth effect on fetuses; thus, it was named "the growth hormone of pregnancy." oPL may 
be also secreted into the mother's blood and enhance some metabolic $(3,4,8,9)$ and mammogenic (13) functions. However, there are conflicting results in respect to the luteoprotective role of oPL. According to Gregoraszczuk et al. (11), oPL has luteoprotective effects, but according to Al-Gubory et al. (2), it is impossible to demonstrate such effects.

At early pregnancy, maternal oPL activates endometrial glands and secretion of uterine milk (5). Moreover, oPL is a prolactin (PRL) related hormone and stimulates mammary growth in the last trimester of pregnancy (7). Earlier studies (10) revealed that the most dynamic changes in mammary blood flow (MBF) occur in ruminants during the periparturient period. We hypothesized that changes in udder temperature and blood hemodynamics during the periparturient period may be related to the disappearance of oPL from the circulation due to ongoing parturition.

The goal of the present study was to analyze the relationship between the decreasing oPL plasma concentration and changes in thermal and blood circulation indices in the udder in periparturient ewes. Moreover, we sought to compare mammary thermal and hemodynamic parameters in single- and twin-pregnant sheep.

\section{Material and methods}

The experiments were carried out on 8 control (nonpregnant) and 15 experimental (pregnant) BCP line sheep (crossbreed Polish Lowland Sheep $\times$ Charolaise $\times$ Berrichone du Cher $\times$ Romanov $\times$ Olkuska) from a herd in the research station in Bezek that belongs to our University. The age of ewes ranged from 2 to 6 years. They weighed $65 \mathrm{~kg}$ on average $(57-72 \mathrm{~kg})$. All animals were synchronized as a part of the artificial insemination procedure. The feed consisted of $200 \mathrm{~g}$ concentrate/ewe/day and meadow hay ad libitum. Throughout the experimental period, the ewes were kept in a sheepfold, remained in good health and did not show any clinical signs of disease. At lambing, the number of lambs born to each ewe, their sex and birth weight was recorded. Experimental design and all the procedures were approved by the Local Ethics Committee for Animal Experimentation in Lublin (License No. 99/2018).

All measurements were conducted by the same persons, in the morning, between 7-8 a.m., before feeding.

From the $6^{\text {th }}$ day before parturition ( $-6^{\text {th }}$ day) to the $4^{\text {th }}$ day post partum $\left(4^{\text {th }}\right.$ day $)$, every second day ewes were subjected to color Doppler ultrasound performed with continuous wave equipment (My Lab One/Touch, Esaote) and infrared thermography (IRT), which allowed for noninvasive collection of data. At the same time, blood samples were
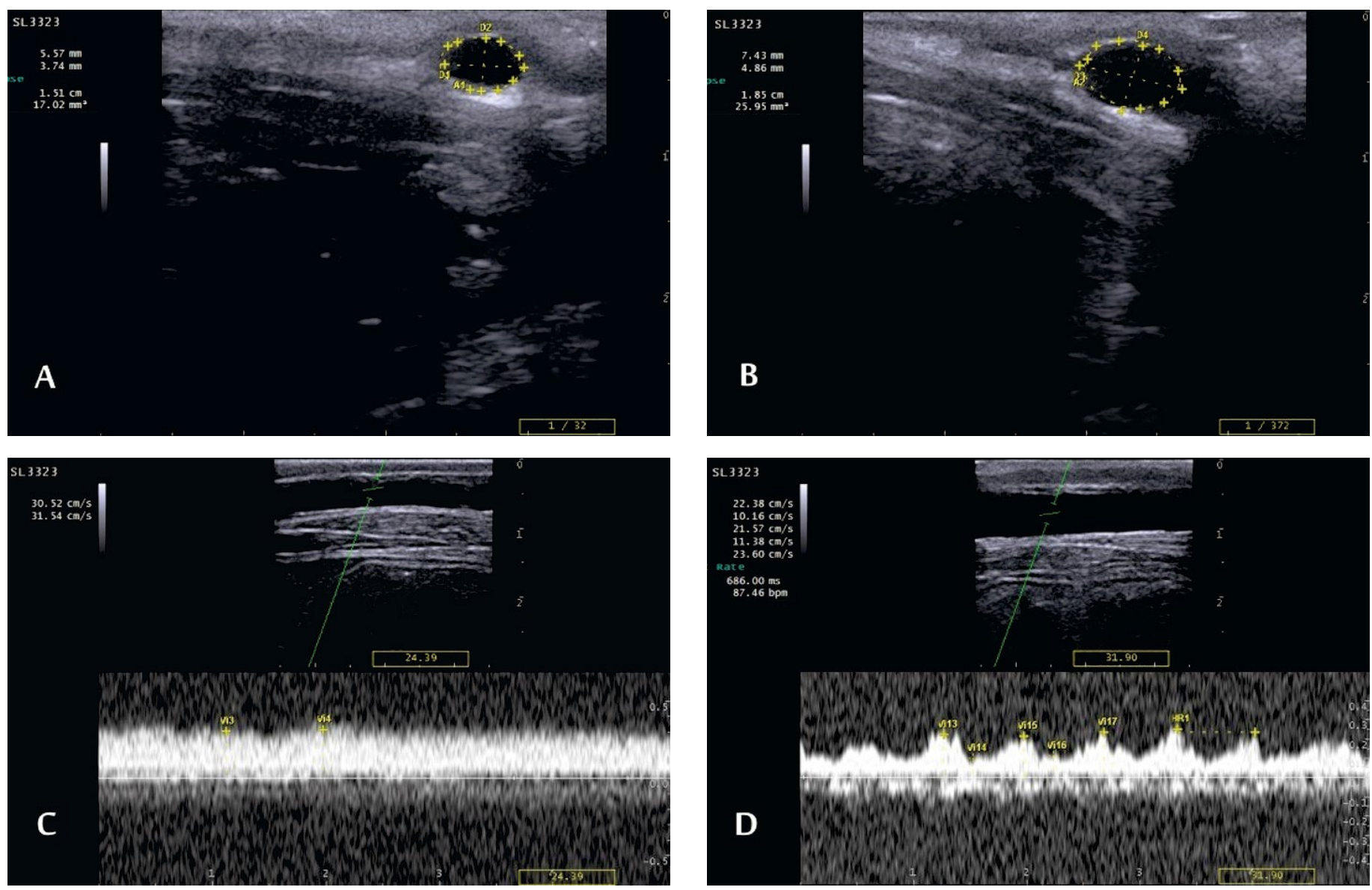

Fig. 1. USG of ewe right mammary vein (RMV) before parturition $(A, C)$ and at the day of parturition $(B, D)$

Explanations: $\mathrm{B}$ - mode presentation (cross-section of RMV two days before parturition $-\mathrm{A}$, and at the day of parturition - B) and spectral recording of blood flow (monophasic flow two days before parturition $-\mathrm{C}$, and flow with slight physiological oscillations in waveforms at the day of parturition - D). Although the diameter of RMV slightly increased, blood velocity and blood flow decreased at the day of parturition (Fig. 1B) 
collected from the jugular vein and the plasma was saved for further analysis.

Doppler measurements were performed on the same spot of the right milk vein of each animal, in pulsed-wave mode (Fig. 1) with an instrument equipped with a 7-14 MHz linear transducer. The milk vein was recognized in all ewes in B-mode and confirmed as a vessel when the cross-section of the vessel averaged $24.22 \pm 5.21 \mathrm{~mm}^{2}$. Blood flow waveforms were obtained at an interrogation angle of $60^{\circ}$ to $80^{\circ}$ between the Doppler ultrasound beam and the flow direction. Blood flow parameters - i.e. blood flow, blood flow velocity and vein diameter - were calculated by a computer from the product of blood velocity and the cross-sectional area of the milk veins.

Infrared thermography (IRT) or thermal imaging utilizes a thermal camera constructed according to the Stefan-Boltzmann law which states that energy emitted in the form of heat is proportional to the temperature of the object. A portable IRT camera (Flir E40) generates images that reflect the amount of heat emitted by the udder skin. IRT image is characterized by darker colors for cooler places and lighter colors for warmer places. In the obtained visual and numeric components of the thermogram, each pixel refers to a temperature value (14). The camera operated within the 8 to $14 \mu \mathrm{m}$ spectral band and the accuracy was $\pm 0.15^{\circ} \mathrm{C}$. Because there were no significant differences in udder surface temperatures between the left and the right gland, all thermograms were taken from defined rectangular $(5 \times 4 \mathrm{~cm})$ areas comprising adjoining parts of both glands on the caudal surface of the udder. Before each measurement, the camera was adjusted for the ambient temperature conditions of each scanning $\left(9-26^{\circ} \mathrm{C}\right)$ to compensate for the reference temperature. All data were recorded, collected and subsequently calculated off-line.

Plasma oPL concentration was determined with a quantitative sandwich ELISA Kit specified for sheep placental lactogen 1 (oPL) (MyBioSource, Inc.). The intra- and inter-assay coefficients of variation were $<6.4$ and $<8.8 \%$, respectively. Statistical analyses were conducted using ANOVA software. Differences of $\mathrm{P} \leq 0.05$ were considered significant. All values were expressed as mean and standard deviations.

\section{Results and discussion}

Experiments were performed in the early days of June, with mean indoor temperatures of 21.20 $\pm 22.10^{\circ} \mathrm{C}$. All lambs were delivered alive. The hemodynamic parameters of the right mammary vein were registered in the non-pregnant ewes $(n=8)$. The right mammary vein blood flow (MVBF), mammary vein blood velocity (MVBV), and cross-section area of the vessel averaged $1.26 \pm 0.46 \mathrm{ml} / \mathrm{s}, 6.78 \pm 0.78 \mathrm{~cm} / \mathrm{s}$ and $16.86 \pm 4.40 \mathrm{~mm}^{2}$, respectively. The abovementioned values were comparable with that of other authors (20).

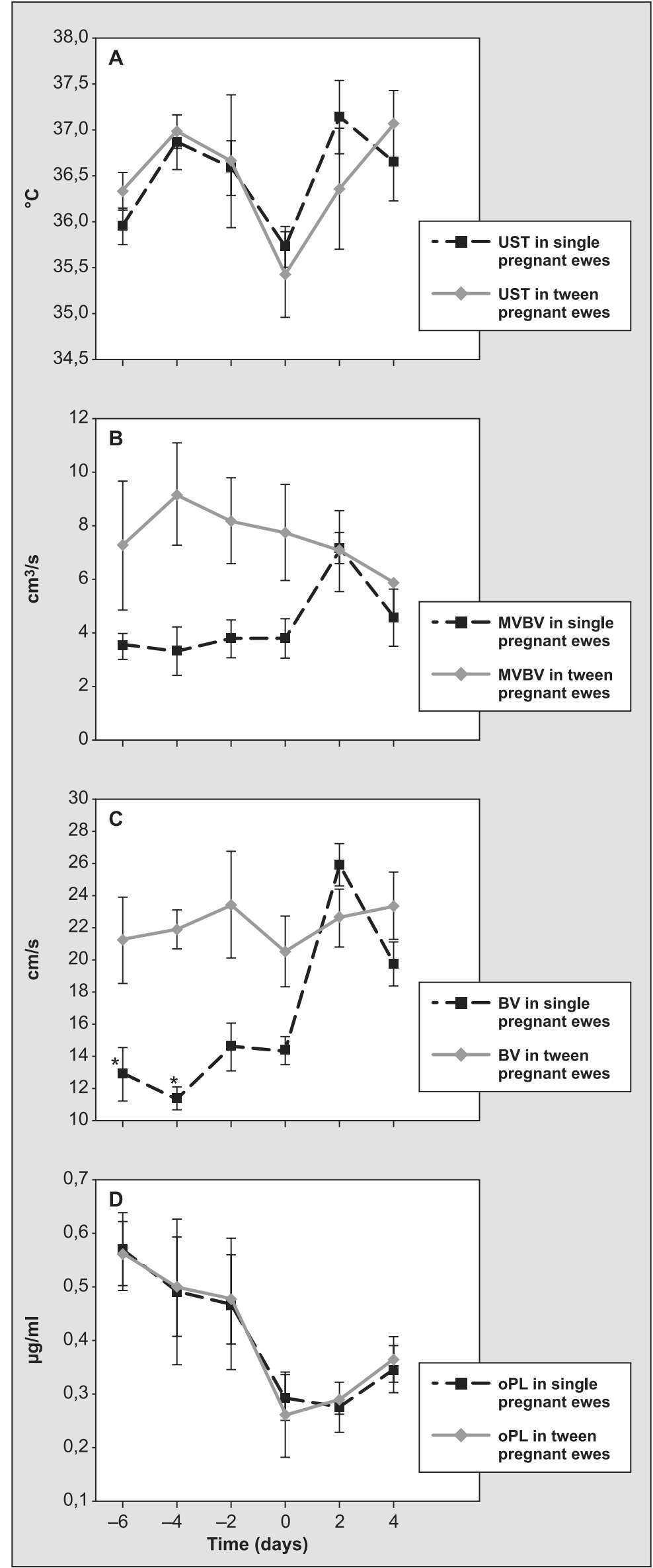

Fig. 2. Changes in udder skin temperature (UST) (A), blood flow parameters $(B, C)$ and concentration of ovine placental lactogen $(0 P L)(D)$ in single and tween pregnant ewes $(n=15 ; \bar{x} \pm S D)$ 

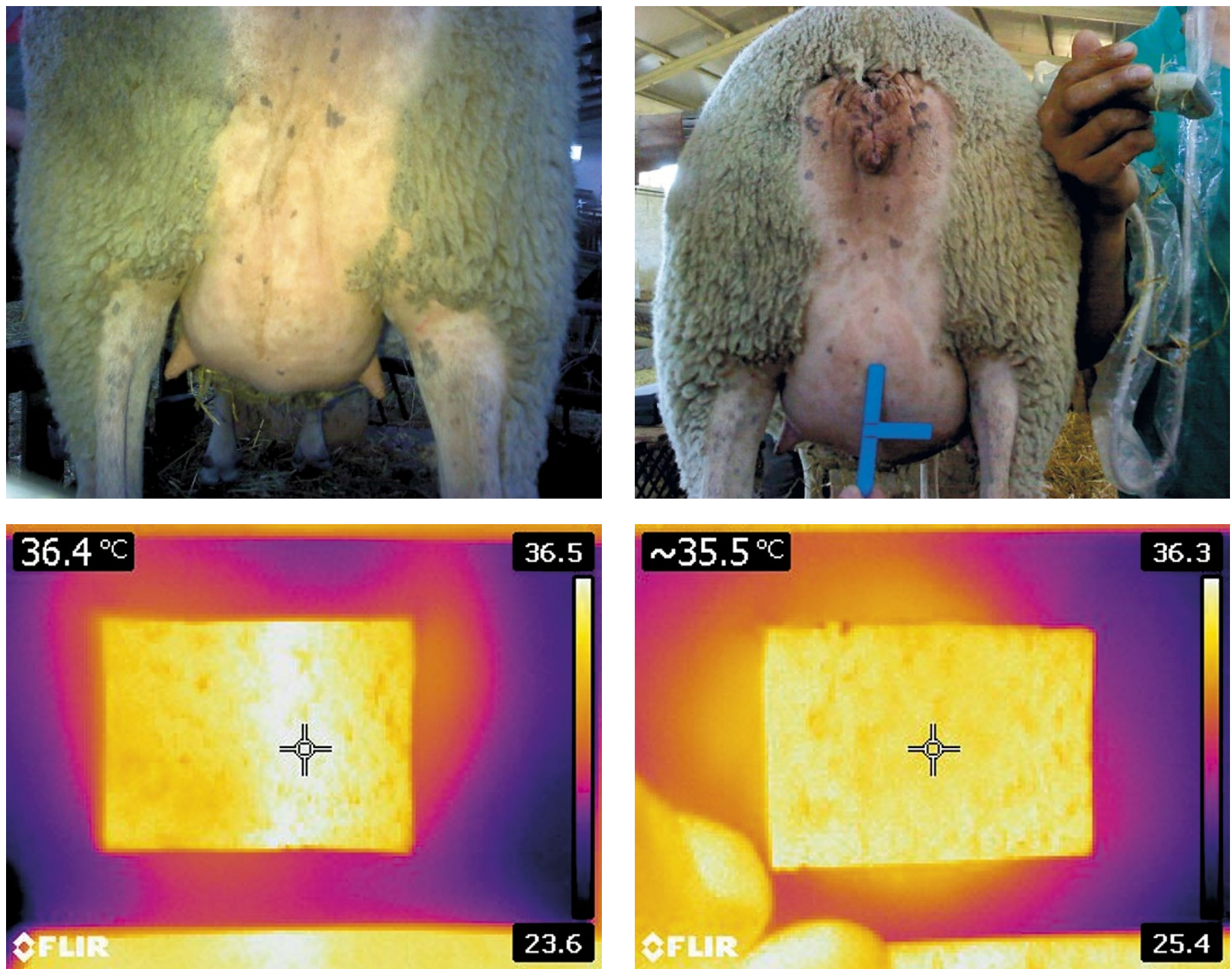

Central thermography of ewe udder two days before parturition

Central thermography of the udder of the same ewe at the day of parturition

Fig. 3. Infrared thermography scan of ewe udder skin temperature (UST) two days before (A) and at the day of parturition (B)

Infrared thermography (IRT). The obtained values of udder skin temperature (UST) $\left(35.67^{\circ}-36.86^{\circ} \mathrm{C}\right)$ were less by about $2^{\circ} \mathrm{C}$ than the values given by Adams and McKinley (1) and higher by about $4^{\circ} \mathrm{C}$ than those given by Castro-Costa et al. (6) (Fig. 3). Such discrepancy results from breed differences and the actual physiological state. All mammary IRT measurements in the healthy pregnant ewes were conducted to compare the obtained values to the blood flow through the mammary vein and to the oPL plasma concentration. The values of UST were affected by the periparturient period, but not by the number of lambs delivered (Fig. 2A). Before parturition, the shape of the UST curve in ewes with single and twin pregnancy was essentially similar, without any significant differences between the groups. The highest udder temperatures were recorded at four days before parturition, which was followed by their gradual decrease (Fig. 3). Accordingly, at the day of parturition, the UST achieved the lowest values in both single- and twin-pregnant ewes (35.70 \pm 0.65 and $35.42 \pm 0.45^{\circ} \mathrm{C}$, respectively). After parturition, UST in ewes with singletons increased to $37.10^{\circ} \mathrm{C}$ on the $2^{\text {nd }}$ day, and on the $4^{\text {th }}$ day in ewes with twins (Fig. 2A).

Among all measured points of IRT and oPL, a significant $(\mathrm{P} \leq 0.01)$ positive correlation was estimated between -4 and 0 days before parturition for single$(\mathrm{r}=0.99)$ and twin-pregnant ewes $(\mathrm{r}=0.59)$.

Right mammary vein blood flow. MVBF during the course of the study was dependent on time and on the oPL level. The right MVBF significantly $(\mathrm{P} \leq 0.05 \%)$ increased during the study in all pregnant ewes in comparison to control ewes. Twin pregnancies were associated with higher MVBF rates than single pregnancies (Fig. 2B). In single-pregnant ewes, blood flow was considerably lower $(4.32 \pm 0.94 \mathrm{ml} / \mathrm{s})$ 4 days before parturition than in twin-pregnant ewes $(9.16 \pm 2.39 \mathrm{ml} / \mathrm{min})$. From that time on, blood flow in single-pregnant ewes gradually increased, with a peak on the $2^{\text {nd }}$ day postpartum $(7.16 \pm 1.11 \mathrm{ml} / \mathrm{min})$. 
The time course curve reflecting blood flow values in twin-pregnant sheep depicts a continuous decline until the postpartum period (Fig. 2C). Especially in twin-pregnant ewes, the correlation between plasma concentration of oPL and blood flow occurred between days -4 and $0(\mathrm{r}=0.76)$.

Mammary vein blood velocity. In single-pregnant ewes, blood velocity (BV) continuously increased in the period between the $4^{\text {th }}$ day before and the $2^{\text {nd }}$ day after parturition. The maximal velocity of blood in the mammary vein was reached on the $2^{\text {nd }}$ postparturient day in single-pregnant ewes $(25.90 \pm 5.95 \mathrm{~cm} / \mathrm{s})$ and on the $4^{\text {th }}$ postparturient day in twin-pregnant ewes $(24.62 \pm 4.86 \mathrm{~cm} / \mathrm{s})$ (Fig. 2C). However, a considerable decrease of MVBV (to the value of $20.53 \pm 4.25$ $\mathrm{cm} / \mathrm{s}$ ) was observed in twin-pregnant ewes during the time of parturition. On the other hand, comparing blood velocity with the values of oPL concentrations reveals a negative correlation $(r=-0.35$ and $r=-0.99)$ in single- and twin-pregnant ewes.

Plasma oPL. The changes in plasma ovine placental lactogen concentrations during the periparturient period are illustrated in Fig 2D. The highest values of plasma oPL $(0.56 \pm 0.05 \mu \mathrm{g} / \mathrm{ml})$, recorded at the beginning of the experimental period ( 6 days before parturition), dropped significantly $(\mathrm{P} \leq 0.05)$ on the following days, until parturition. Plasma placental lactogen achieved the lowest (almost undetectable) values at parturition $(0.27 \pm 0.06 \mu \mathrm{g} / \mathrm{ml})$. Subsequently, an unexpected slight elevation in the plasma oPL concentration was observed. The curve of the changes in the concentration of plasma PL remains unchanged regardless of the number of fetuses (Fig. 2D).

This study demonstrates that before parturition, mammary blood flow parameters are significantly $(\mathrm{P} \leq 0.05)$ elevated in relation to the control group, especially in twin-pregnant ewes. The blood flow in the right mammary vein was significantly smaller in single- than in twin-pregnant ewes. From six days before parturition, RMVBF gradually increased in single-pregnant ewes. However, in twin-pregnant animals augmentation of RMVBF was only temporary and was only observed between the $6^{\text {th }}$ and the $4^{\text {th }}$ day before parturition. At the day of parturition both RMVBF and blood velocity decreased, which was clearly visible in the group of twin-pregnant ewes. After parturition, these indices rose abruptly. Similarly to the data obtained after parturition in cows $(4,10)$, we observed a substantial elevation of RMVBF and blood velocity two days after parturition in single-lambing ewes. Such changes may result from a marked increase of PGF $2 \alpha$ in the blood due to its enhanced production and secretion by uterine tissues and mammary gland just before parturition $(17,18)$. Vasoconstrictive effects of this prostanoid combined with diminished levels of vasodilatatory PGE2 and PGI2 are presumably responsible for biphasic hemodynamic oscillations in the periparturient period in ewes. The fact that PGF $2 \alpha$ disappears from the circulation after parturition is reflected by elevated blood velocity and RMVBF at least in twin-lambing ewes. In agreement with earlier data $(10,16)$, our results emphasized that during the transition from pregnancy to lactation MBF may depend on both vessel diameter and blood flow velocity (BFV), but mainly on blood velocity during the lactation period. Furthermore, as it is shown in Figure 2B, $\mathrm{C}, \mathrm{D}$, the disappearance of oPL from the circulation is combined with a considerable increase in mammary blood flow (RMVBF) and blood velocity in singlepregnant ewes without significant changes in twinpregnant ewes. Differential effects of blood velocity in the right mammary vein on RMVBF were observed in both groups of pregnant ewes. While in the group of single-pregnant ewes the increase in blood velocity had a significant influence on blood flow, in the group of twin-pregnant ewes this effect was minimal. The results obtained before parturition indicate that the decreasing plasma oPL concentration in both groups of ewes is associated with a significant continuous increase in blood flow only in single-pregnant ewes. In the group of twin-pregnant ewes, the biphasic response was initially observed to increase, and later to decline. In the light of the above statements, attention should be given to the vasoconstrictive effects of PL. At least in humans and pigs, PL provokes hypertension through enhancement of vasoconstriction mediated by $\beta 2$-adrenergic receptors blockade leading to inhibition of nitric oxide release (15). Our results obtained before parturition demonstrated that the subsequent disappearance of oPL from the circulation is connected with an increase in blood velocity. It should be emphasized that we found similar changes in plasma oPL in both groups of ewes. Despite the contrary results of other authors, the lack of differences between the levels of oPL in our single- and twin-pregnant ewes may ensue from the fact that only one isoform of this compound hormone protein was analyzed in our study.

The udder in ruminants radiates heat and can lose about $7 \%$ of heat, i.e. $388 \mathrm{~W} / \mathrm{m}^{2}$ (12). This value is dependent on the ambient temperature and blood flow rate (6). Moreover, it is believed that reduction of the mammary vascular bed by vasoconstriction is the only reason for the decreasing UST (as suggested by Castro-Costa et al.) (6). Due to the above, when external temperature was relatively stable (around $21-22^{\circ} \mathrm{C}$ ), we expected, in relation to our experimental periparturient ewes, that varying blood flow into the udder influenced UST. However, fluctuations in blood flow were only slightly related to the thermal changes, but strongly associated with the lowering concentrations of oPL in the prepartum period. In both groups of ewes, UST began to rise six days before parturition. But in the subsequent days before delivery, both UST and oPL concentrations decreased. Therefore, based on 
the results of our study it may be assumed that dropping UST is coupled with the decreasing concentration of oPL. The highest thermography values recorded 4 days before parturition $\left(36.90^{\circ} \pm 0.62^{\circ} \mathrm{C}\right.$ and $37.10^{\circ}$ $\pm 1.18^{\circ} \mathrm{C}$ in single- and twin-pregnant ewes, respectively) were negatively correlated with plasma levels of PL ( $\mathrm{r}=-0.99$ and $-0.59, \mathrm{P}<0.01$, respectively). Moreover, at the time of parturition, a negative correlation was found between thermography parameters and plasma levels of oPL in both groups of ewes. However, the decrease in UST observed during the last 4 days before parturition was coupled with dropping oPL concentrations in both groups of ewes. It comes as no surprise then that a positive correlation was established at these time points between the values of UST and oPL concentrations. The lack of differences between oPL concentrations in single- and twin-pregnant ewes throughout the entire experimental period was reflected in similar temperature oscillations in both groups of ewes.

Our studies reveal that fluctuating thermal and hemodynamic parameters around parturition in ewes remain in association with the gradually decreasing levels of oPL.

In conclusion, three-phasic thermal changes in the mammary gland in the periparturient period and the increase in blood flow parameters remain in correlation with the disappearance of oPL from the circulation and should be taken into account when we clinically assess this gland due to its pathological state.

The following essential conclusions can be drawn from this study:

1) The profile of changes in udder temperatures in ewes remains in relation mostly to blood velocity, except for parturition time,

2) The considerable fall in udder temperature in the periparturient period is related to the drop in plasma oPL,

3) In contrast to blood flow parameters, the changes in udder temperature are almost on the same level for single- as well twin-pregnant ewes.

Therefore, our experimental results shed light on the involvement of the disappearance of oPL in the changes in both UST and hemodynamic parameters of the ewe udder in the periparturient period.

\section{References}

1. Adams D., McKinley M.: The sheep. ANZCCART Fact sheet A9. Australian and New Zealand Council for the Care of Animals in Research and Teaching. The University of Adelaide, Adelaide, Australia 2009

2. Al-Gubory K. H., Camous S., Germain G., Bolifraud P., Nicole A., CeballosPicot I: Reconsideration of the proposed luteotropic and luteoprotective actions of ovine placental lactogen in sheep: in vivo and in vitro studies. J. Endocrinology 2006, 188, 559-568.

3. Braun T., Li S., Moss T. J. M., Newnham J. P., Challis J. R. G., Gluckman P. D., Sloboda D. M.: Maternal betamethasone administration reduces binucleate cell number and placental lactogen in sheep. J. Endocrinology 2007, 194, 337-347.

4. Braun U., Forster E., Bleul U., Hässing M., Schwarzwald C.: B-mode and colour Doppler ultrasonography of the milk vein and musculophrenic vein in eight cows during lactation. Res. Vet. Sci. 2013, 94, 138-143.
5. Burton G. J., Fowden A. L.: Review: the placenta and developmental programming: balancing fetal nutrient demands with mathernal reasource allocation. Placenta 2012, 33 (suppl), S23-S27.

6. Castro-Costa A., Caja G., Salama A. A. K., Rovai M., Flores C., Aguiló J. Thermographic variation of the udder of dairy ewes in early lactation and following an Escherichia coli endotoxin intramammary challenge in late lactation. J. Dairy Sci. 2014, 97, 1377-1387.

7. Forsyth I. A., Hutchings A., Butcher G. W.: A panel of monoclonal antibodies to ovine placental lactogen. J. Endocrinol. 2000, 165, 435-442.

8. Fowlkes J., Freemark M.: Binding of placental lactogen and growth hormone to fetal sheep fibroblasts. Pediatr. Res. 1992, 32, 200-203.

9. Gootwine E.: Placental hormones and fetal-placental development. Anim. Reprod. Sci. 2004, 82-83, 551-566.

10. Götze A., Honnens A., Flachowsky G., Bollwein H.: Variability of mammary blood flow in lactating Holstein-Friesian cows during the first twelve weeks of lactation. J. Dairy Sci. 2010, 93, 38-44

11. Gregoraszczuk E. L., Zięba D., Wierzchoś E., Murawski M., Gertler A.: Placental lactogen as a regulator of luteal cells function during pregnancy in sheep. Theriogenology 2000, 53, 877-885.

12. Kifle G. G., Wu B.: Modeling heat loss from the udder of dairy cow. J. Therm. Biol. 2016, 59, 34-38.

13. Leibovich H., Gertler A., Bazer F. W., Gootwine E.: Active immunization of ewes against ovine placental lactogen increases birth weight of lambs and milk production with no adverse effect on conception rate. Anim. Reprod. Sci. 2000, 64, 33-47.

14. Metzner M., Sauter-Louis C., Seemueller A., Petzl W., Klee W.: Infrared thermography of the udder surface of dairy cattle: characteristics, methods, and correlation with rectal temperature. Vet. J. 2014, 199, 57-62.

15. Molinari C., Grossini E., Mary D. A. S. G., Ribichini F., Surico N., Vacca G.: The role of nitric oxide in the peripheral vasoconstriction caused by human placental lactogen in anaesthetized pigs. Exp. Physiol. 2006, 91, 603-610.

16. Nielsen M. O., Jakobsen K., Jørgensen J. N.: Changes in mammary blood flow during the lactation period in goats measured by the ultrasound Doopler principle. Comp. Biochem. Physiol. 1990, 97A, 519-524.

17. Nielsen M. O., Nyborg S., Jakobsen K., Fleet I. R., Nørgaard J.: Mammary uptake and excretion of prostanoids in relation to mammary blood flow and milk yield during pregnancy-lactation and somatotropin treatment in dairy goats. Domest. Anim. Endocrin. 2004, 27, 345-362.

18. Nielsen M. O., Schleisner C., Jakonsen K., Andersen P. H.: The effect of mammary $\mathrm{O}_{2}$ uptake, $\mathrm{CO}_{2}$ and $\mathrm{H}^{+}$production on mammary blood flow during pregnancy, lactation and somatotropin treatment in goats. Comp. Biochem. 1995, 112A, 591-599.

19. Spencer T. E., Sandra O., Wolf E.: Genes involved in conceptus-endometrial interactions in ruminants: insights from reductionism and thoughts on holistic approaches. Reproduction 2008, 135, 165-179.

20. Zoma W. D., Baker R. S., Kopernik G., Mershon J. L., Clark K. E.: Differential effects of selective estrogen receptor modulators and estrogens on mammary blood flow in the ovine. Am. J. Obstet. Gynecol. 2002, 187, 1555-1560.

Corresponding author: Prof. dr hab. Ryszard Bobowiec, ul. Akademicka 12, 20-033 Lublin, Poland; e-mail: ryszard.bobowiec@up.lublin.pl 